\title{
Family bliss or blitz? Parents' and children's mixed emotions towards family holidays
}

\section{Malene Gram, Anette Therkelsen and Jacob Roesgaard Kirkegaard Larsen}

\begin{abstract}
Purpose - This paper aims to explore mixed emotions experienced by parents and children on holiday, how they are dealt with and how they influence the way "family" is "staged" and "done".

Design/methodology/approach - This paper draws on 24 qualitative interviews with Danish parents and a questionnaire study reporting answers from 66 Danish children (11-15-year-old).

Findings - Problems external and internal to the family are identified and the latter are associated with more unease particularly among parents. This paper shows that parents invest significant narrative efforts in transcending gaps between ideals and practices. Also children are aware of the gaps between ideals and practices; they seem more matter-of-fact, however, regarding critical aspects of holidays.

Research limitations/implications - The informants of the study solely represent two-parent heterosexual families of Danish origin, and so inclusion of a wider range of families would have added interesting perspectives. Furthermore, children's perspectives on critical holiday incidents need further research.

Practical implications - Creators of family holiday products and marketing should present a more nuanced imagery taking a more diverse approach to what "family" on holiday looks like. They could take up the challenge of depicting a broader range of family situations, also showing less harmonious moments, using humour, and showing opportunities for some "alone time" for both parents and children should relational overload happen. Also occasional "wifi-free" moments seem to be much appreciated by all family members, and development of offline family experiences would seem to strike a chord.

Social implications - The contemporary paradigm of intensive parenting along with strong ideals for family holidays make it essential for parents to narratively deal with and legitimize and transform less happy moments. To take pressure off contemporary families, it is important to bring to the fore the less glossy aspects of family holidays.

Originality/value - The originality of this paper is to illustrate the strong efforts applied by families to keep up a certain front to be the family that "ought to be" by nurturing and narrating positive emotions in relation to family holidays. The inclusion of children's voices gives insights into children's annoyance with parents' rowing, relational overload and parents' occasional lack of attention to children, for example through parental use of mobile phones during holiday togetherness.
\end{abstract}

Keywords Family identity, Coping strategies, Family holidays, Intergenerational relations, Consumer ambivalence, Family performance

Paper type Research paper

\section{Introduction}

Family holidays are imagined to be happy times and enable reconnecting as a family (Nickerson and Jurowski, 2001; Backer and Schänzel, 2013). Holidays, however, are part of everyday family practices and consumption (Hall and Holdsworth, 2016; Larsen, 2008), and it seems relevant to understand family holidays in the context of dominant ideologies on happy family life and the importance of successful parenthood (Douglas and Michaels, 2004; Miller, 2012). Despite the fact that in practice the holiday is part of the ups and downs
Malene Gram and Anette Therkelsen are both based at Aalborg University, Aalborg, Denmark. Jacob Roesgaard Kirkegaard Larsen is based at Dansk Kyst-og Naturturisme, Aabybro, Denmark.

(c) Malene Gram, Anette Therkelsen and Jacob Roesgaard Kirkegaard Larsen. Published by Emerald

Publishing Limited. This article is published under the Creative Commons Attribution (CC BY 4.0) licence. Anyone may reproduce, distribute, translate and create derivative works of this article (for both commercial and non-commercial purposes), subject to full attribution to the original publication and authors. The full terms of this licence may be seen at http:// creativecommons.org/ licences/by/4.0/legalcode

The authors would like to thank the parents and children who generously offered their time and shared their experiences in this study. The authors wish to thank the EU Structural Fund for funding parts of the two projects from which the present study draws its data: "Holiday Houses of the Future" and "Hostels for children". In addition, thanks are extended to Maria Lottrup for undertaking the interviews for the project "Hostels for children".

Received 13 June 2017 Revised 3 September 2017 3 November 2017 20 December 2017 Accepted 3 January 2018 
of contemporary family life, an unhappy family holiday seems to be in contrast to ideals of family life (Carr, 2011), which should be characterized by "joyful 'familyness'" (Haldrup and Larsen, 2003). Perhaps because of the inherent expectation of family holidays as being outside everyday life, the darker sides of family holidays have not received much attention (exceptions are studies by Obrador, 2012; Backer and Schänzel, 2013; Hall and Holdsworth, 2016). In this paper, we explore the less happy aspects of family holidays, how they give rise to mixed emotions among family members and how they are dealt with.

Mixed emotions or consumer ambivalence have been studied in the context of other types of consumption (Otnes et al., 1997; Penz and Hogg, 2011) including consumption of weddings (Otnes et al., 1997) and advertisements (O'Donohoe, 2002), but less so in the context of holiday consumption. Consumer dissatisfaction has been studied in a tourism context, often referred to as critical incident studies (Alegre and Garau, 2010) conducted in the context of the service meeting at restaurants and hotels (Andersson and Mossberg, 2004) or at the destination as a whole (Pritchard and Havitz, 2006). Research is, however, scarce on the complex and often contradictory emotions families hold in relation to holidays. Positive and negative emotions relate to not only service meetings encountered during a holiday but also to the interpersonal relations of the family. This paper explores what happens when conflicts between sociocultural ideals and experienced practices (Miller, 2012) occur. Critical holiday moments may question the social functioning of the family, and with that the family's identity, if left unresolved. Conversely, critical moments may strengthen the family, if coped with by the family members. Hence the aim of the paper is to explore critical incidents experienced by parents and children on holiday, how they are dealt with through coping strategies and eventually how they influence the way family is "staged" and "done". The contribution of this paper is to understand the critical incidents of family holidays within the wider context of sociocultural ideals and identity relating to families, through the voices of both children and parents, and to reflect on the implications of this for tourism professionals.

Empirically, the paper draws on 24 qualitative interviews with Danish families and a questionnaire study reporting answers from 66 Danish children (11-15-year-olds).

\section{Consumer ambivalence: the ideal and the real family holiday}

It is argued that consumption in general is an inherent part of being and doing family (Epp and Price, 2008) just as consumption of holidays is part of family performance (Obrador, 2012). Strong norms and ideals exist in regard to what a family should be like (Miller, 2012), e.g. that relations between family members should be close, childhood should be happy and that family holidays should be good times. And so people often find themselves in the dilemma between ideals and the actual state of a consumption situation, as being a family does not always coincide with these ideals. Particularly the mother seeks to "diminish the discrepancy between [...] the normative and the actual" (Miller, 2012, p. 70) and through pragmatism and compromising to close the gap between what "is" and what "should be". To understand how families deal with discrepancies between "the real" and "the ideal", socio-cultural norms towards families must be understood (Miller, 2012). "Family" is not a fixed and static unit, but is rather a fluid state of being and a process of doing (DeVault, 1991; Huff and Cotte, 2016; Hall and Holdsworth, 2016) and it needs to be displayed to have social reality (Finch, 2007). Parents seek to demonstrate that they live good parenting, and displaying family is described as a process of defining and redefining a situation, when several competing interpretations are possible (Finch, 2007). Good parenting, and particularly good mothering, implies living up to a certain image, not least self-sacrifice (Badinter, 2010).

Obviously, parents do not blindly seek to replicate the happy, perfect family holiday as communicated in glossy advertisements but have a critical awareness of the difference between the ideal and the real. Nonetheless, this idealized imagery taps into social norms, 
aspirations and expectations of family in contemporary society. Family life is imbued with strong normativity and carries along demands, which may be difficult to reconcile with family practice (Douglas and Michaels, 2004) - not at least when on holiday (Hall and Holdsworth, 2016). Obrador (2012), who studied British families holidaying in Menorca, wrote: "Nowhere is the family at play as prominent as on the beach and by the hotel pool. These are socially constructed spaces for the modern family to play, they are privileged stages for the display of love, unity and tenderness" (p. 414). Family holidays are linked with high expectations of family bliss, in contrast to the mundane life at home and assumed to be: "ideal time, therefore trouble free" (Hall and Holdsworth, 2016, p. 290). As such, holidays are seen as important for family bonding (Carr, 2011) and reconnecting as a family (Backer and Schänzel, 2013). In practice, however, holidays are part of family everydayness (Hall and Holdsworth, 2016) in that parental chores of feeding and caring for their children as well as family relations, and possibly conflicts do not disappear because the physical context changes. Hence the holiday can be experienced as "enforced periods of over-intimacy" (p. 298). In other words, while differentiation seems to characterize the ideal holiday, de-differentiation (Larsen, 2008; Uriely, 2005) is an important characteristic of holiday practices, and as such closely connected to everyday practices (Hall and Holdsworth, 2016). And like the everyday, family holidays are seldom just harmonious (Johns and Gyimothy, 2002; Obrador, 2012; Hall and Holdsworth, 2016). Holidays may be "stressful" with "an increase in unpleasant tasks and irritations and not a relaxing and enjoyable experience" (Backer and Schänzel, 2013, p. 159). This may give rise to mixed emotions and ambivalence:

Beneath the image of a united, stable, loving family there are multiple conflicts and tensions: Holidays that do not match up to expectations; conflicting interests: parents that are tired of being with their children all the time; wives that feel frustrated with their husband's inclination to do nothing (Obrador, 2012, p. 416).

That families on holiday uphold an image of loving unity, even though tensions and conflicts are lurking beneath (Obrador, 2012), points towards Goffman's dramaturgical metaphors of performance and staging of everyday life (Goffman, 1959). Goffman found that people perform "fronts" and seek to manage how they are perceived by others, particularly people external to the family unit. "Performance", "staging" and "fronts" are apt concepts to understand how families communicate about their holidays and their challenges when asked to relate also more difficult sides of family holidays. Drawing on Goffmann's concept of "script", Ferguson and Veer (2015) found that bungy jumping offers a narrow and disciplined "script" with few alternative ways of performing the jump. In contrast, the family holiday has quite a broad script which family members need to fill out and enact. Living up to expectations, while adhering to the norms and ideals of good parenting and happy holidays, becomes more challenging.

Consumer ambivalence is argued to be triggered by an interplay between internal emotional struggles and external social and cultural forces (Otnes et al., 1997). Otnes et al. conceptualized consumers' experience of mixed emotions in the market place and how these are linked to coping strategies. They argued that internal struggles between pleasant and unpleasant feelings for the same object as well as external forces, such as the existing social structure, are both sources of mixed feelings: "individuals must often reconcile conflicting demands placed on them as they attempt to enact various social roles - each characterized by norms and counter-norms that govern role behaviour. When such norms clash, ambivalence often results" (p. 82). Consumer ambivalence is argued to stem from factors such as expectation versus reality, overload and custom and value conflict. These factors tally with those of Miller's study (2012) in which social norms play a considerable role in the evaluation of the quality of family practices. Mixed emotions lead consumers to act because they are motivated to avoid negative emotions (Otnes et al., 1997; Penz and Hogg, 2011) and hence they turn to coping strategies. Coping strategies such as finding 
compromises between various family members' wishes are well-documented in the family holiday literature (Bronner and de Hoog, 2008; Gram, 2005; Therkelsen, 2010) but also Otnes et al.'s (1997) coping strategy "resignation" seems to hold explanatory power as parents are known to give in to their children's demands to achieve harmony. Moreover, resignation may lead to momentary parental withdrawal from family togetherness, which is in line with a study on family caravanning holidays (Mikkelsen and Blichfeldt, 2015). Finally, socio-cultural ideals of harmonious family togetherness may lead to a strategy of turning bad experiences into good ones, such as finding the positive aspects in poor weather and laughing off rude staff. Having their mind set on a successful family experience, parents may seek to avoid negative emotions by diminishing unpleasant incidents thereby sustaining family identity both internally and externally (Finch, 2007). However, as Löfgren (2000) convincingly argued, positive experiences often presuppose tristesse, waiting, boredom and routine, but the question is whether families acknowledge the benefit of negative feelings and experiences in a holiday context.

Unsurprisingly, research shows significant differences between parents' and children's holiday preferences, and mixed emotions are likely to materialise both among parents and children during the course of a holiday (Obrador, 2012; Carr, 2006). What seems to prevent holidays from turning into miserable events for both parents and children is a shared goal of being together (Cederholm, 2007; Ek et al., 2008; Lehto et al., 2009).

Little research exists on difficult aspects of the family holiday, particularly in a Scandinavian context, even though studies find that holidays are more like everyday life than earlier research has led us to believe. Subsequently, we explore how family members labour to reconcile what "is" and what "should be". Even though children are well known to be important voices in family decision-making (Ebster et al., 2009; Gram, 2015) not least when holidays are concerned (Gram, 2007; Therkelsen, 2010), little research involves children's views on good and bad sides of the holidays. In the following section, the inclusion of children's voices demonstrates their ambivalence towards family holidays, even though they are less attentive to socio-cultural norms and thus less careful about the family front than adults.

\section{Method and empirical data}

The current article is based on an interpretive, explorative approach (Kvale, 1996) and it seeks to uncover new insights into family performance and mixed emotions in a family holiday context. For this reason, priority is given to both parents' and children's voices. Interviews with Danish families constitute the main empirical data; however, as the children contributed minimally in the interviews, a supplementary questionnaire study among Danish children (11-15-year-olds) was conducted.

The parental perspective is covered by two sets of data from self-organized, self-catering tourists collected in the spring/summer 2012-2014: interviews with 12 families while on holiday in coastal holiday homes and 12 families after their holidays in camping sites or family hostels. The interviews lasted approximately $1 \mathrm{~h}$. The age of the parents ranged from late 20s to early 40s and their children ranged from 0-6 years (small children) to 7-15 years (older children) or a mixture of the two. Both in terms of educational and professional backgrounds and place of residence, a broad cross-section of Danes was represented. The multi-faceted nature of the data offers insights into a wide set of perceptions of family holidays. The interviews were carried out by one of the authors and two research assistants and the family members were interviewed together. The advantage of this was that all family members addressed a shared "family reality" - reflecting on the same holiday incidents. The disadvantage was that the parents most often controlled the dialogue. The informants were not particularly prompted to address unhappy moments; rather they were asked about their holiday preferences, their previous experiences and the activities of their present or most recent holiday. The interview audio files were transcribed verbatim and quotes 
translated into English by the authors. All interviewees were ensured anonymity. Interviews include families who are in "the thick of it", which offers insights that would possibly be forgotten or left out if the families were interviewed after the holiday. These interviews were combined with retrospective interviews, in that a process of reflection may result in other family staging mechanisms being put to use. In the Danish context, ethical clearance must be given from informants themselves and from parents when children are involved. Consent to participate was obtained from all participants, or parents of participants, and they were informed that withdrawal from the interview was possible at any time.

To get children's voices clearly represented in the data, 20 Danish schools were approached during spring/summer 2015. The schools were situated in areas with a broad middle class population to ensure an approximately similar social background of the informants in the two sets of data. Four schools accepted to participate. The schools were asked for permission to make an online questionnaire available for 12-14-year-olds. This age group was chosen because the researchers wanted to make sure that the respondents could express their experiences and emotions in writing. The questionnaires were kept short to accommodate children's limited span of attention (Banister and Booth, 2005). There were no relations between the parents and children interviewed in 2012-14 and the children participating in the questionnaire study in 2015. It would have strengthened the data if parents and children had belonged to the same families thereby referring to the same "reality", but still parents and children are referring to meanings and expectations of holiday experiences in the same cultural setting. The questionnaire builds on the same overall topics as the interviews, though direct questions were included relating to less good holiday experiences. Parents were asked for consent through the schools.

A total of 66 pupils filled in the questionnaire, 56 per cent boys and 44 per cent girls. A total of 3 per cent were 11 years, 47 per cent were 12, 17 per cent were 13, 32 per cent 14 and 2 per cent were 15 years of age. Despite the limited response rate, the questionnaires offer perspectives on good and bad holiday experiences valuable to this explorative study. Most questions were open for qualitative answers, which resulted in several well-reflected answers from these relatively young respondents. SurveyXact was used for constructing and distributing the questionnaires, as well as for summarising the data. All quotes were translated into English by the authors.

With point of departure in the research literature presented above, the analysis was carried out through an exploration of the families' holiday accounts along with the children's answers to the questionnaire. The data were synthesized and analysed through a thematic approach (Kvale, 1996) based on a categorization of family external and internal causes for mixed emotions.

All inputs from children in the article stem from the questionnaire study. Even though we find the responses from the children insightful, in future studies we would prefer to use qualitative face-to-face interviews instead, preferably drawing on various techniques such as collages and simulation games to gain more in-depth data from young informants.

\section{The Danish holiday context}

With a minimum of five weeks of paid holiday plus bank holidays annually for all employees, Denmark outranges most other countries in terms of holidays (www.thelocal.dk/20150407/ working-in-denmark-vacation-and-holidays; www.workindenmark.dk/Working-in-DK/Holiday-pay; accessed August 21, 2017). Families often spend 2-4 weeks together at home, abroad or a combination of the two during the summer. This is very different from for example the USA where long family holidays are not the norm. The family interviews were all conducted in Denmark during or after the holiday, and stories were told about holidays in Denmark and elsewhere. The children were contacted just after the summer holidays, and they similarly commented on holidays in Denmark and abroad. It is not unusual for Danish children to have holiday 
experiences from several countries (Blichfeldt et al., 2011). As Danish mothers and fathers are typically active on the labour market, children are most often in day-care, kindergarten, school and afterschool care, and thus family members are used to leading individual lives in each of their workplace or institution. This means that the expectation of intense togetherness during holidays may be a particularly significant challenge in Denmark. Even though adults take relatively long summer holidays, many keep in touch with their jobs through smart phones, ipads and computers, and thus mentally do not log off completely (www.businessdanmark.dk/ Inbusiness-forside/InBusiness-artikelarkiv/2015/Q3/Sluk-mobilen-og-hold-ferie/ accessed August $21,2017)$. This is a topic high on the agenda of Danish media during the summer period.

\section{Findings}

Next, adults' and children's accounts of good holiday experiences are presented, followed by accounts of critical incidents, first caused by external then by internal family issues. These experiences are linked to consumer ambivalence and how this is coped with.

\section{Happy family holiday experiences - living up to "the ideal"}

Holidays are associated with being pleasurable by both parents and children in this study. Parents' express that they seek to be together as a family, which is in line with the extant literature. Being away from home means being away from chores and segregated lives. Being together is typically defined in contrast to everyday life where tight time schedules generated by work, school/day-care and spare time activities limit time spent together. Hence unplanned time on holiday seems to compensate for the scheduled time of everyday life, which is illustrated by one family who highlights its "duvet day" (mother, Family 11): a rainy day where they stayed in their pyjamas all day. Another parent explains being together like this:

It is more that we have been together, we have had no plans. We have had dinner, when the barbeque was ready, right. We have not been busy. I guess this is what has been most important (mother, Family 9).

The parents express that unplanned time facilitates togetherness, relaxation and social bonding. Doing something together (swimming, going for a walk, visiting fun parks and zoos and shopping) seems to tie a family together both during the activity and when the stories are told after the event. Activities are to a significant extent undertaken to cater for the children's demands as they otherwise get bored, which underlines the willingness to sacrifice own desires in the name of intensive parenthood.

The children mainly define the good holiday with reference to activities undertaken and attractions visited. Integral to these activities, however, is also an appreciation of being together with the family:

Last year we went to Greece together. It was really cosy as the internet did not work that well. That meant that we had to be together. We also relaxed more. Normally we do a lot of sightseeing but this year we only visited three sights. Apart from that we just relaxed at the beach and by the pool (girl, 14 years).

Hence absence from everyday routines in terms of strict timetables and familiar settings, both on part of their parents (work) and themselves (being in school or with friends) and facilities (internet access), is generally valued as it leaves time for being and doing things together with the family. "At home, homework, music, sports, school and friends take up my time. But on holidays you are together with them [parents]" (boy, 14 years); "We play games and are together instead of being preoccupied with each our mobile phone"(girl, 13 years); "My parents can't work on Aaland [a Finnish group of islands] and therefore they are more together with us" (girl, 13 years). 
Even though differences exist between parents and children in terms of how they define "the good holiday", they agree that being and doing various activities together is central. Parents are particularly attentive to the demands of their children both to compensate for every day segregated lives and to avoid conflicts, and children seem likewise to be concerned with ensuring harmony, and mention that they like when parents are not online and not working when on holiday. This is in line with the growing family holiday literature stressing family togetherness through child-centred activities (Carr, 2011; Gram, 2007; Therkelsen, 2010). Wishing to be together and being attentive towards each other are characteristics which live up to socio-cultural prescriptions of the ideal family holiday as pleasurable. In this study, no one dismisses holidays as failures, even though they may involve certain tensions.

\section{Unhappy holiday incidents external to the family}

All parents recognize that negative incidents and tension can form part of a family holiday. However, they more readily acknowledged problems caused by the service provider, the infrastructure or the weather than problems caused by conflicts and disagreements within the family. Problems such as rented accommodation not living up to standards advertised, including untidy outside facilities and low-level cleaning standards, are mentioned, but seem only to cause momentary annoyance and are typically handled by contacting the accommodation rental service. Poor sign posting and road work are also examples of externally caused problems, which in one case resulted in a family never reaching the heritage site planned for. The father's account is, however, made in a humorous tone:

We ended up in a parking lot. From there we could see the site in the distance but we couldn't get over there [...] So we could just conclude: "Kids, over there are the Stones of Jelling [the heritage site]" (father, Family 13).

Even though deficiencies in the infrastructure could have been blamed, a potentially bad experience is coped with by turning it into a funny story that the family is able to laugh at afterwards, and so the unfortunate incident is not allowed to inflict negatively on the holiday. Though ambivalent feelings are traceable in this clash between expectations and reality, the family, or at least the father, is staged as competent in coping with such an issue through humour, thus preventing a critical situation from escalating.

Turning a potentially bad experience into something good is a coping strategy that is also detectable in a family who missed the tour bus back from a day out in Mallorca. The mother relates:

We were out there in a tiny village, were cold, and didn't really know what to do. Then we found an inn which actually was closed, and they only had one dish that we could get. And it was rabbit and we were kind of... [rabbits are pets, not food, in Denmark]. I think we said to [name of daughter] that we did not really know if this meant hare or rabbit because otherwise she might have... [unclear]. But we got, we got rabbit. And it was a fantastic experience. Really a fantastic food experience which we really will remember as something extra [...] And it is a little cool that they are up to this kind of thing, the kids (mother, Family 11).

A less-than-perfect situation (being cold, lost, hungry and forced to eat pets) is turned into a memorable experience of the holiday (Löfgren, 2000), and in addition, it becomes an opportunity to praise their children for their openness to new food. The appropriateness of the children's behaviour reflects positively back on their parents' own skills at parenting, just as the family's ability to handle a delicate situation makes them stand out in their staging of themselves as a competent family. This is a way of saving, perhaps even strengthening, the family front by adhering to the ideal script (Goffman, 1959) for family holidays.

The questionnaire study shows that the large majority of children answered "yes" (75 per cent) when asked if a holiday could be less good. However, several children answered that 
they have no personal experiences with bad holidays: "because when I am on holiday with my family it is always fun' (boy, 14 years); "because it is always cosy to be with your family" (girl, 14 years). One respondent reflects: "A completely bad holiday would take a lot. There must be something good in the holiday" (girl, 12 years), thus underlining that complete holiday failure is unlikely. Hence the sociocultural ideal of "the good holiday" also appears in the children's holiday staging efforts and hence like adults they adhere to the family holiday script (Goffman, 1959; Ferguson and Veer, 2015).

The children were asked to give reasons as to why holidays could be bad. As with the parents, potentially bad experiences fall into categories of family external and family internal issues. Family external issues mainly address the weather, like for instance: "The worst holiday I had was last summer where it rained almost all days and we had a flood in our caravan" (boy, 14 years); "We were in the Philippines, and there was wild lightening, my father, little sister and I were totally scared (I thought we were going to die)" (boy, 14 years). Potential dangers at the holiday destination are also identified ranging from losing personal items: "having my Nintendo stolen" (girl, 14 years) to feeling personally endangered: "if there has been an accident" (girl, 14 years); "if you don't feel safe" (girl, 14 years); "food poisoning" (girl, 14 years); "breaking a leg or an arm" (boy, 12 years); "being burnt by a jelly fish" (boy, 12 years); and the more imaginative one: "being kidnapped" (boy, 14 years). These dangers are, however, just stated and not exemplified which indicate that such critical incidents are not central to the children's experiences of holidays.

In sum, the parents do not allow shortcomings of the destinations to interfere with the family's performance of the happy holiday. Problems are coped with in practice by finding pragmatic solutions, including adapting to destination conditions, and narratively through humour and turning bad experiences into good stories. Through these coping strategies, the family is staged as a competent, closely-knit entity which family ideals prescribe. The children likewise identify a number of critical incidents related to the destinations. The children, however, seem matter-of-fact about the critical incidents and do not identify coping strategies. This difference in the data may, however, partly be a consequence of using a questionnaire as opposed to face-to-face data collection, and it would probably have offered important information to ask children about one specific holiday in more depth. But it may also be a matter of parents adhering more strictly to the family holiday script and being more concerned with staging the family as competent.

\section{Unhappy holiday incidents internal to the family}

According to the parents, problems arising from within the family relate to their children getting bored or fighting among themselves or with the parents, as well as different expectations in relation to what and how many activities should be included in the holiday. One parent states that their children are "entertainment demanding", which is at odds with their own preferred activity level. Similarly, another family relates:

I: Do you have fewer conflicts when you are on holiday, compared to home?

M: Actually I think. . . it is only the last couple of days there has been [...] between those two [daughter 1 and daughter 2]. They are like night and day. So. . . and then she [daughter 3] who just tries to [...] well [...] follow suit. So I think the last couple of days there has been some [...]. You start to feel saturated and start to have the need to get back to your room and your things and...well. Not that you can't [...] you can go in here and close the door, but there isn't anything in those rooms other than a bed, and then they have brought some things along. No, I actually think it has been relatively painless.

F: Yes. I also think they are getting tired.

M: Yes, that's what we choose to believe [haha]" (father and mother, Family 9). 
These parents' struggle to put into words what happens around them. The mother's sentences are fragmented, self-interrupted and restarted seven times, searching for the appropriate wording of this difficult situation where the "family performance" is out of tune with ideals for the close-knit family. This indicates that family skirmishes are unpleasant to reveal, and illustrates Finch's (2007) point of defining and redefining a situation to be able to display the family adequately. "Being saturated" is a way of saying that one has had enough, and "being tired" is a more diplomatic expression of being unpleasant to be around. Still within the same breath, the mother states that the week has been "relatively painless". In relation to norms of the good holiday, "painless" is a low criterion of success, but seems acceptable to the mother. Hence the children's behaviour is justified in view of the unusual, 24/7 family togetherness of a holiday, and by offering such explanations, the problems are sought minimized. In line with Goffman (1959) and Obrador (2012), a perfect front stage is sought maintained through the narrative efforts of the mother, though cracks appear and reveal certain tensions.

Being together is stated as the overall aim of this family's holiday, but relational reconnection can at times turn into over-intimacy (Hall and Holdsworth, 2016), for the children, and for the parents as well: "The first 4-5 days it went well. It was only yesterday that it started to get like I began thinking: "Okay, where can we send them away on holiday? [haha]" (mother, Family 9). Sending the children away on holiday, while on holiday with them, demands a laugh from the mother, and it is obviously at odds with her own definition of the good family holiday. Another parent is more open about the difficult sides to the family holiday, explaining that everyday problems follow along when the family goes holidaying: "it [a holiday] does not run smoothly. It never does when a family is together" (father, Family 7).

Even if the close co-habitation takes place without too much trouble, it is perhaps not always as fantastic as imagined. Asked if their holiday lives up to their expectations, one father says: "I guess it does" (father, Family 3) without much enthusiasm. Generally speaking, mothers in the interview study worked harder at keeping up the family front than fathers, which may indicate a gendered expectation of women as responsible for family bliss.

Negotiations between social prescription and individual wishes also appear in relation to views on children's holiday clubs. Not being with the children is seen as wrong, which fits well into the current family ideology underlining intensive parenthood and importance of closeness and interest in the children. This, however, makes holiday time very intense, and it appears that parents also enjoy time apart from their children:

M: Sometimes we have visited Legoland and their hotel. And it is really nice for the children as well [...]. They have a children's section where the children can play with Lego. Then they are away from us and we can sit and talk together, right.

F: Yes.

M: And of course this is good fun for the children.

F: It is just for a short while, right (mother and father, Family 13).

Socio-cultural ideals of family togetherness are at odds with personal desires here in that the parents enjoy some time alone. Justification of their actions is called for: they state that their children enjoy the play activities and that the activities only go on for a short while. Hence the image of the "good parent" is intact in that being and doing things together is only dispensed from for a short while to cater for the children's wishes. Opting out of "doing family" for a while calls for legitimization and is also detectable in the subsequent example of a father who explains that he does not want to do activities with his children all the time: "Sometimes you also want to just lie down a bit and relax on your holiday, don't you?"(father, Family 21). He thus underlines that it is just "sometimes" and just "a bit", and he seeks confirmation by adding "don't you?" This shows that he narratively labours at living up to family ideals. The parents' consumption of family holidays, and the ensuing good stories 
and pragmatic solutions to problems encountered, function to narrow the gap between the practice of the family, which is perhaps not always ideal, and the family that "ought to be" and has to be appropriately staged. In this way the parents present themselves according to the dominant ideology of the fulfilled family to which all the families in this sample seem to aspire.

From the perspective of the children, family internal issues can be related to wrong choices being made in view of the children's preferences, sometimes for the sake of younger siblings. This leads to boredom and dissatisfaction with parental choices as expressed in this quote:

For example when I was in Astrid Lindgren's world [Swedish theme park]. It was not much fun because it was for younger children and I could not chose not to come along (boy, 14 years).

Moreover, social overload is an issue identified by the children also: "If you have siblings, the fact that you have to be with them 24/7, they may get on your nerves" (girl, 13 years) and "That you have to do the same as everybody else all the time" (boy, 14 years). Hence as found by Small (2008), ambiguity in relation to family togetherness is expressed among the children, and as opposed to the parents, they do not seek to cover this up.

The most significant source of unhappy holiday experiences mentioned by several children concerns family members, particularly parents, not living up to expectations of having a good time together when being on holiday: "If one's parents are not into having a good time and are just working" (boy, 11 years); "I spent time at my father's place and we did not really do anything because he just spent time with his girlfriend" (girl, 12 years). Children mention rows in the family as negative: "if your parents are having rows" (girl, 13 years); "if you have a row with a family member" (boy, 12 years). Like parents, children adhere to the family holiday script of pleasant togetherness; however, unlike the parents, they seem less concerned with upholding the family "front" (Goffman, 1959). Children's expectations of "having a good time" and doing activities together with their parents are not met in these examples, which seem to cause feelings of disappointment and rejection.

In sum, family internal issues seem more critical than destination-related issues for both parents and children as they evoke feelings of disappointment, rejection and fear of failure, which threaten the harmony of the family and with that family identity. When unhappy incidents are addressed by parents, they are accompanied by a laugh or excuses such as explanations of tired children missing their daily routines and surroundings. In this way the ideal family front stage is maintained in that family holidays are first and foremost presented as happy. The children are mainly happy with their holidays, but are less concerned with maintaining the family front and identify critical issues such as not getting attention from parents or the occurrence of family rows without cover-up strategies. This indicates that the family holiday script is not as ingrained in children as it is in parents.

\section{Discussion and conclusion}

The aim of this study has been to explore how family holidays give rise to ambivalent feelings among parents and children, and findings show how gaps between sociocultural ideals and experienced practice are transcended through holiday narratives, particularly among parents, and how families use holidays for staging their family identity.

Going on holiday is assumed to be an integral part of family life (Hall and Holdsworth, 2016), and not going on holiday among middle-class families almost call for an excuse in the Danish context. Consuming holidays are part of family practices and an important objective relates to interaction and bonding among family members. In this study, going away from home is mentioned as important and mostly pleasant, and the challenge seems to be to strike the right balance of activities and having a bit of space for oneself (Schänzel and Smith, 2014). Ups and downs seem unavoidable when families spend time together, but the "downs" demand legitimization. Shortcomings are coped with through humour, turning bad experiences into 
good stories and finding alternatives/adapting to destination conditions, and in that process staging the family as a competent, closely-knit entity.

Externally caused problems are most easily discussed by both children and parents. Internally caused emotions of irritation, rejection or social overload are experienced by both parents and children, but are more difficult to relate for parents. Moments of irritation seem to arise from sometimes too long and too intense togetherness, and these critical moments appear to be countered by including activities that particularly suit the children. When irritation is addressed in the interviews, this is followed by a laugh and a joke, or it is explained that the children are tired and missing their rooms and toys at home. Hence distinctive discursive work is used to stage holidays as family bliss, and critical incidents are not allowed to alter this image, thereby ruling out the existence of a holiday induced family blitz. The wish to overcome consumer ambivalence and transcend the gap between ideals and practice in relation to holidays translates into coping strategies. This signifies that family holidays are central in demonstrating successful parenting to present-day parents.

While the children in the study are generally happy with the family holidays, they are also more open in their accounts of difficult internal issues such as rows between parents, feeling overlooked, or opting out of family togetherness. Hence the children do not labour to present a perfect family front to the same extent as the parents, which may rest with children being less tied down by the family holiday script.

The contribution of this article is to further the discussion on family and family holidays in the consumer behaviour literature by adding to our understanding of the darker sides of family holidays. This is done by applying the concept of consumer ambivalence, research on family and consumption and Goffman's theory of staging. The consumer ambivalence perspective includes not only critical incidents of the service meeting, which the existing literature has focused on so far, but also studies (Obrador, 2012; Backer and Schänzel, 2013; Hall and Holdsworth, 2016) that begin to address the not-so-harmonious aspects of family holidays. By exploring the tensions of family holidays in more depth, the article illustrates the strong efforts applied by parents to keep up a certain front (Goffman, 1959) and to stay within the "script" (Ferguson and Veer, 2015) of family holidays: to be "doing" (DeVault, 1991) and "displaying" (Finch, 2007) the family that ought to be (Miller, 2012) by nurturing and narrating positive emotions in relation to family holidays.

A further contribution of the study is related to the inclusion of children's voices on happy and unhappy holiday moments, which adds to our understanding of family holidays and the dilemmas between socio-cultural ideals and consumer practices, including the differences between parents' and children's needs for staging family identity through holidays. The children included in the study offer significant observations on parents' difficulties in abstaining from work or being absorbed in their mobile phones, which is in conflict with children's expectations of togetherness. The children's observations supplement the family interviews in important ways. Children bring to light that it is not just parents who think that their children are too much online, but that children find that their parents are, too. Furthermore, it is a new finding that children also experience emotional overload from being too much together; and that they detest their parents rowing. These are issues that parents do not bring up - either because they do not see them or do not wish to address them. As children's voices have been heard to a modest extent in marketing, consumer behaviour and tourism literature, this is a significant contribution.

A few limitations of the study and future avenues for research are worth reflecting on. It would have strengthened the article with a more thorough inclusion of children's perspectives on critical holiday incidents than offered by the questionnaires used in this study. More research is needed to include children further through in-depth qualitative research methods, which would add more substance to the insights presented here. The authors find that there is more to be gained within this field of research from further including children's perspectives, which to a high 
extent have been overlooked in marketing, consumer and tourism research. The informants of this study mainly represent two-parent families of Danish origin, and so single parent families, same-sex marriages and families of different ethnicities or several generations are not represented. Including a broader array of families would have added interesting perspectives to the discussion on ideals versus practice. A closer look at how consumption more specifically plays into mixed emotions, for example how consumption-oriented coping strategies might come into play to achieve family harmony in family holidays, would be interesting to explore in future studies, just as an exploration of mixed emotions in the light of the experiential consumption and destination management literature will be a relevant perspective to pursue.

The implications of this study are of social significance as the maintenance of "the perfect family" cultivated in market communication towards families is not helpful for families struggling to do "family". The unrealistic imaginings of happy families put pressure on families with children. In relation to marketing implications, the strong inherent that particularly parents face of what "should be" and "what is", are important for marketers of products for families to understand. With an understanding of these dilemmas, destination and tourism marketing managers will be able to offer a more nuanced imagery taking a more diverse approach to what "family" on holiday looks like. In this way what "should be" could be approximated to what "is" in families, and would be attractive to contemporary families, who feel squeezed when failing to enact the unequivocally happy family of the glossy brochures. Aligning marketing closer with family holiday practices not only holds commercial potential it could also serve a higher purpose of reducing the social pressure put on modern families.

In staging a more nuanced image of families on holiday, in line with the findings of this article, humour could resonate well with a preferred parental coping strategy. If done with finesse making fun of bad family holiday incidents and showing how these can be turned into good experiences, as parents in this study do, would be likely to appeal to parents. Other parental coping strategies could also be translated into tourism marketing and destination development actions in that avoidance and withdrawal could be accommodated by offering opportunities for parental "alone time" and peerto-peer time for children. A contribution of this study is the finding that also children sometimes suffer from relational overload, and that just like parents they sometimes need space.

Both parents and children emphasize that they enjoy time offline together on holiday, and possibly wifi-free zones for at least some offline time together would be attractive for all family members. Tourism professionals could offer more experiences where all family members are immersed, and where it is not possible to be standing on the sideline with a smartphone.

\section{References}

Andersson, T.D. and Mossberg, L. (2004), "The dining experience: do restaurants satisfy customer needs?", Food Service Technology, Vol. 4 No. 4, pp. 171-177.

Alegre, J. and Garau, J. (2010), "Tourist satisfaction and dissatisfaction", Annals of Tourism Research, Vol. 37 No. 1, pp. 52-73.

Backer, E. and Schänzel, H. (2013), "Family holidays, vacation or Obli-Cation", Tourism Recreation Research, Vol. 38 No. 2, pp. 159-173.

Badinter, E. (2010), Le Conflit: La Femme Et La Mere, Flammarion, Paris.

Banister, E.N. and Booth, G.J. (2005), "Exploring innovative methodologies for child-centric consumer research", Qualitative Market Research: An International Journal, Vol. 8 No. 2, pp. 157-157.

Blichfeldt, B.S., Pedersen, B.M., Johansen, A. and Hansen, L. (2011), "Tweens on holidays, In-situ decision-making from children's perspective", Scandinavian Journal of Hospitality and Tourism, Vol. 11 No. 2, pp. 135-149. 
Bronner, F. and de Hoog, R. (2008), "Agreement and disagreement in family vacation decision-making", Tourism Management, Vol. 29, pp. 967-979.

Carr, N. (2006), "A comparison of adolescents' and parents' holiday motivations and desires", Tourism \& Hospitality Research, Vol. 6 No. 2, pp. 129-142.

Carr, N. (2011), Children and Families' Holiday Experiences, Routledge, London and New York.

Cederholm, E.A. (2007), "At" bare være" - ægthed relationer og intimitet i oplevelsesindustrien", in Bærenholdt, J.O. and Sundbo, J. (Eds), Oplevelsesøkonomi - Produktion, Forbrug, Kultur, Samfundslitteratur, Copenhagen, pp. 277-299.

DeVault, M. (1991), Feeding the Family: The Social Organization of Caring as Gendered Work, Chicago University Press, Chicago.

Douglas, S. and Michaels, M. (2004), The Mommy Myth: The Idealization Of Motherhood And How It Has Undermined All Women, The Free Press, New York, NY.

Ebster, C., Wagner, U. and Neumueller, D. (2009), "Children's influence on in-store purchases", Journal of Retailing and Consumer Services, Vol. 16 No. 2, pp. 145-154.

Ek, R., Larsen, J., Hornskov, S.B. and Mansfeldt, O.K. (2008), "A dynamic framework of tourist experiences: space-time and performances in the experience economy", Scandinavian Journal of Hospitality and Tourism, Vol. 8 No. 2, pp. 120-140.

Epp, A.M. and Price, L.L. (2008), "Family identity: a framework of identity interplay in consumption practices", Journal of Consumer Research, Vol. 35 No. 1, pp. 50-70.

Ferguson, S. and Veer, E. (2015), "3-2-1 Bungy: a typology of performance styles", Annals of Tourism Research, Vol. 55, pp. 61-76.

Finch, J. (2007), "Displaying families", Sociology, Vol. 41 No. 1, pp. 65-81.

Goffman, E. (1959), Presentation of Self in Everyday Life, Doubleday Anchor Books, New York, NY.

Gram, M. (2005), "Family holidays: a qualitative analysis of family holiday experiences", Scandinavian Journal of Hospitality \& Tourism, Vol. 5 No. 1, pp. 2-22.

Gram, M. (2007), "Children as co-decision makers in the family? The case of family holidays", Young Consumers, Emerald Group Publishing, Vol. 8 No. 1, pp. 19-28.

Gram, M. (2015), "Buying food for the family. negotiations in parent/child supermarket shopping: an observational study from Denmark and USA", Journal of Contemporary Ethnography, Vol. 44 No. 2, pp. 169-195.

Haldrup, M. and Larsen, J. (2003), "The family gaze", Tourist Studies, Vol. 3 No. 1, pp. 23-45.

Hall, S.M. and Holdsworth, C. (2016), "Family practices, holiday and the everyday", Mobilities, Vol. 11 No. 2, pp. 284-302.

Huff, A.D. and Cotte, J. (2016), "The evolving family assemblage: how senior families 'do' family", European Journal of Marketing, Vol. 50 Nos 5/6, pp. 892-915.

Johns, N. and Gyimothy, S. (2002), "Mythologies of a theme park: an icon of modern family life", Journal of Vacation Marketing, Vol. 8 No. 4, pp. 320-331.

Kvale, S. (1996), Interviews, SAGE Publications, London.

Larsen, J. (2008), "De-exoticizing tourist travel: everyday life and sociality on the move", Leisure Studies, Vol. 27 No. 1, pp. 21-34.

Lehto, X.Y., Choi, S., Lin, Y. and MacDermid, S.M. (2009), "Vacation and family functioning", Annals of Tourism Research, Vol. 36 No. 3, pp. 459-479.

Löfgren, O. (2000), "Interviewed in Weekendavisen", 22-28 September by Pernille Stensgaard.

Mikkelsen, M.V. and Blichfeldt, B.S. (2015), "We have not seen the kids for hours': the case of family holidays and free-range children", Annals of Leisure Research, Vol. 18 No. 2, pp. 252-271.

Miller, D. (2012), Consumption and its Consequences, Polity Press, Cambridge.

Nickerson, N.P. and Jurowski, C. (2001), "The influence of children on vacation travel patterns", Journal of Vacation Marketing, Vol. 7 No. 1, pp. 19-30.

Obrador, P. (2012), "The place of the family in tourism research: domesticity and thick sociability by the Pool”, Annals of Tourism Research, Vol. 39 No. 1, pp. 401-420. 
O'Donohoe, S. (2002), "Living with ambivalence: attitudes to advertising in postmodern times", Marketing Theory, Vol. 1 No. 1, pp. 91-108.

Otnes, C., Lowrey, T.M. and Shrum, L.J. (1997), "Towards an understanding of consumer ambivalence", Journal of Consumer Research, Vol. 24 No. 1, pp. 80-93.

Penz, E. and Hogg, M.K. (2011), "The role of mixed emotions in consumer behaviour: investigating ambivalence in consumers' experiences of approach-avoidance conflicts in online and offline", European Journal of Marketing, Vol. 45 Nos 1/2, pp. 104-132.

Pritchard, M.P. and Havitz, M.E. (2006), "Destination appraisal”, An analysis of critical incidents, Annals of Tourism Research, Vol. 33 No. 1, pp. 25-46.

Schänzel, H. and Smith, K. (2014), "The socialization of families away from home: group dynamics and family functioning on holiday", Leisure Sciences, Vol. 36 No. 2, pp. 126-143.

Small, J. (2008), "The absence of childhood in tourism research", Annals of Tourism Research, Vol. 35 No. 3, pp. $772-789$

Therkelsen, A. (2010), "Deciding on family holidays: role distribution and strategies in use", Journal of Travel and Tourism Marketing, Vol. 27 No. 8, pp. 765-779.

Uriely, N. (2005), "The tourist experience: conceptual developments", Annals of Tourism Research, Vol. 32 No. 1, pp. 199-216.

\section{About the authors}

Malene Gram is Associate Dean for Education in the Faculty of Social Sciences and Associate Professor of Consumer Culture at the Department of Culture and Global Studies, Aalborg University, Denmark, where she is part of the research group Culture and Consumption and member of the Tourism Research Unit. Her research interests are in consumer culture with a special interest in issues related to childhood, perceptions of children and family in relation to consumption in various cultures. Recently she has studied family food negotiations, the consumption of family holidays and intergenerational relationship. She has published in journals such as Journal of Consumer Culture, Journal of Contemporary Ethnography, Journal of Youth Studies, International Journal of Consumer Studies, Advertising and Society Review, Childhood and Journal of Scandinavian Hospitality and Tourism. Malene Gram is the corresponding author and can be contacted at: gram@cgs.aau.dk

Anette Therkelsen is Associate Dean for Research in the Faculty of Humanities and Associate Professor of Tourism Studies at the Tourism Research Unit, Department of Culture and Global Studies, Aalborg University, Denmark. Her research interests include place branding at different geographical scales and various aspects of tourism-related consumer studies. She has published internationally on these topics in, for example, Journal of Consumer Culture, Scandinavian Journal of Hospitality and Tourism, Journal of Leisure Studies, Journal of Vacation Management, Current Issues in Tourism and Journal of Travel and Tourism Marketing.

Jacob Roesgaard Kierkegaard Larsen is Deputy Manager at Coast and Nature Tourism in Denmark. Jacob's PhD dissertation is called "Family Holiday Homescapes. Place, individual and social perspectives on the intra-family experience dynamics at the holiday home destination". Jacob has published in Scandinavian Journal of Hospitality and Tourism and authored several book chapters.

For instructions on how to order reprints of this article, please visit our website: www.emeraldgrouppublishing.com/licensing/reprints.htm

Or contact us for further details: permissions@emeraldinsight.com 